\title{
Children who require long-term assisted ventilation: education and training for care staff
}

Jaqui Hewitt-Taylor RN, RSCN; PhD, BA (Hons), Practice Development Fellow, Children with Complex and Continuing Health Needs, Institute of Health and Community Studies, Bournemouth University, UK

E-mail: jhtaylor@bournemouth.ac.uk

Key words: Children community care education $*$ long-term ventilation health care support workers

\section{SUMMARY}

* Advances in medicine and technology mean that a growing number of infants and children survive with a need for long-term assisted ventilation. This presents a number of challenges to the health service.

* Wherever possible, children should be cared for within their family unit in the community. However, a number of issues, including the availability of staff to provide for their care needs, makes this problematic for children who require long-term assisted ventilation.

* When achieved, community-based care of these children is generally overseen, planned and co-ordinated by registered nurses, but the day-to-day input is often provided by health care support workers. A need has been identified for specific education and training opportunities for this staff group.

* This paper describes the development and evaluation of a pilot distance learning course developed by Bournemouth University and Clinovia Clinical Services, aimed at addressing the needs of health care support workers who care for children requiring long-term assisted ventilation. It includes the rationale for course development, the approach to learning adopted, the findings of the evaluation, and the future direction of course developments as a result of the evaluation.

\section{INTRODUCTION}

There is a growing population of infants and children who require long-term assisted ventilation (Jardine \& Wallis, 1998). In England, the National Service Framework for Paediatric Intensive Care (1998) and the National Service Framework for Children with Complex Needs (Ward et al., 2003) identified the importance of meeting the specific needs of this population.

Traditionally, such children were cared for in intensive care environments. However, this is now generally thought to be an unacceptable long-term option. It is recommended that, wherever possible, children should be cared for within their family unit in the community (National Health Service Executive, 1997). However, for children who require long-term assisted ventilation, the availability of staff to provide suitable home care and support is often a major obstacle to their discharge from hospital (National Health Service Executive, 1997a). Although the care of these children is generally overseen, planned and co-ordinated by registered nurses, the day-to-day input is often provided by care staff who are not registered nurses. A national survey of care managers (HewittTaylor, 2004) indicated that provision of specific education and training for this group of staff would be beneficial. As this population is diverse, and numbers small within each geographical area, distance learning was considered a viable option for education provision.

This paper describes the development and evaluation of a distance learning course developed by Bournemouth University and Clinovia Clinical Services, aimed at addressing the needs of health care support workers (HCSWs) who care for children with longterm assisted ventilation needs.

\section{COURSE BACKGROUND}

Infants and young children are able to survive with increasingly complex medical problems and technical needs, including the need for long-term assisted ventilation. The National Service Frameworks for Paediatric Intensive Care (National Health Service Executive,1997b) and for Children with Complex and Continuing Health Needs (Ward et al., 2003) have identified the importance of meeting these children's specific requirements.

The need for long-term assisted ventilation previously necessitated hospital-based care, usually in an intensive care environment (Lumeng et al., 1999; Kirk \& Glendinning, 2002). However, this is an inappropriate environment for children who have long-term health care needs but are medically stable (Boosfeld \& O'Toole, 2000). Caring for children who require long-term assisted ventilation in an acute intensive care setting is an inappropriate use of resources (Boosfeld \& O'Toole, 2000; Glendinning \& Kirk, 2000). The acute hospital setting is also an undesirable environment for children to develop educationally, psychologically and socially (Neufeld et al., 2001). Wherever possible, children should be cared for at home, where their psychological, developmental and social needs are generally better met (Balling \& McCubbin, 2001; Neufeld et al., 2000). The physical health of children who require 
long-term assisted ventilation is also often improved when they are cared for at home (Jardine et al., 1999).

However, Noyes (2002) found that almost all young people with such needs spend significant amounts of time in hospital when they no longer want or have a medical need to be there. The availability of care staff is often a major obstacle to their discharge from hospital (National Health Service Executive, 1997; Jardine et al., 1999). Increasing the number of such staff is therefore likely to increase the possibility of providing care in the most appropriate environment.

When children who require assisted ventilation are cared for at home, their parents often provide the type of care that is usually seen as the domain of professional staff. In many cases, a lack of viable alternatives means that they feel they have no option but to take on such responsibilities (Kirk, 2001). This means that they must learn about medical and technological aspects of care, make profound adjustments to their everyday lives, cope with a high level of unpredictability, and maintain other family functions within these constraints (Aday \& Wegener, 1998; O'Brien, 2001). The provision of such care 24 hours a day, seven days a week is demanding, and providing support and respite care for families is important (Neufeld et al., 2001; Olsen \& Maslin-Prothero, 2001). However, such support is often difficult to organise and its availability in comparison with need is generally inadequate (Neufeld et al., 2001; Olsen \& Maslin-Prothero, 2001; Robinson et al., 2001). Jardine et al. (1999) found that only $17 \%$ of families providing care for a child requiring assisted ventilation had respite care in place. Given the increasing population of such children, there is an ongoing need to explore how these services can be developed.

Increasing the number of staff who can provide care for this population will potentially improve the quality of life of the children and their families. Such care is generally overseen, planned and co-ordinated by registered nurses, but the day-to-day input is often provided by care staff who are not registered nurses. This may be due to the lack of trained nurses willing to do this type of work (Hewitt-Taylor, 2004). However, it is more likely due to a general shortage of registered sick children's nurses/registered nurses (child), and because registered nurse coverage for a 24hour period is an expensive resource. Although the degree of support needed varies from family to family, Jardine and Wallis (1998) suggest that, with the exception of the care co-ordinator for each child, care staff need not be trained nurses. This situation is not unique to the care of these children in the community setting. Gould et al. (2004) identify that a significant proportion of patient care in the UK is carried out by staff who are not registered nurses. From a quality perspective, Warr (1998) found that where health care support workers are given adequate training opportunities, the standard of care they provide equals, and sometimes surpasses, that of D Grade staff nurses (registered nurses who are either newly qualified or new to a speciality).

Although many health care assistants undertake a competency-based training scheme leading to a vocational qualification (National Audit Office, 2001), these programmes are not specific to caring for children who require long-term assisted ventilation. Jardine and Wallis (1998) suggest that a comprehensive training package should be provided for such staff. They identify that those involved in meeting the child's social, emotional and developmental needs, and the family's education and training, should include all these aspects of care provision. Clinovia Healthcare, who provide home care for children with a range of complex needs, and Bournemouth University have therefore jointly developed a specific learning programme for health care support workers who care for children requiring long-term assisted ventilation. This was piloted between October 2003 and May 2004.

\section{THE COURSE}

Despite the growing population of children needing long-term assisted ventilation, the total number of staff involved in caring for them is relatively limited nationally and small within each geographical area. Staff release at pre-specified times and to prespecified locations is also problematic. These factors, combined with the general difficulty encountered by staff seeking to combine work, study and family life, meant that a distance learning approach with central provision of learning materials supported by local staff was considered to be a viable option. This gave flexibility over exact timing and location of study. Because this was a new development, it was piloted to test the content, level and approach to learning used.

The course comprised a series of eight workbooks covering a range of biological, social and psychological elements of caring for children needing long-term assisted ventilation and their families. Final assessment was determined by a written assignment. Students were drawn from throughout the UK because Clinovia can provide care for children throughout England, Scotland, Wales and Northern Ireland.

Learning is thought to be optimal when students are actively involved in the learning process (McFazdean, 2001) and the design of distance learning materials should embrace this principle. In this instance, presentation of material, interspersed with activities to assist students in reflecting on their practice and linking the course content to the families they care for, was selected to achieve this goal. This approach has been used successfully in post-registration nurse education to assist students in applying theoretical content to their own (potentially diverse) practice situations (Hewitt-Taylor, 2003).

Students using distance learning approaches may feel isolated in their studies, especially if they are unused to this style of learning (McPhee \& Nohr, 2000). Student support was therefore considered to be a crucial factor in course planning. Support was available from the University-based course co-ordinator and the Clinovia nurse education co-ordinator for each geographical region. Local and case specific support was also available from Clinovia's nursing Co-ordinators (registered nurses who supervise the planning and co-ordination of care for individual children and their families within specific geographical areas).

The course commenced with an introductory study day held at two locations, one in the north and one in the south of England. These days were intended to provide students with information about the course, its structure, the approach to learning adopted, resources available and how to access support from course facilitators and other students. It also enabled the students to meet one another and to begin to develop peer support networks.

After eight weeks, during which students began to complete the course workbooks, a plenary session and interim evaluation were held at the two locations. The aim of these days was to allow students to review their work, discuss the workbooks, activities and 
assignments and to gain mutual support. A final plenary day took place at the end of the course, where students gave a brief presentation of their course work and evaluated the course as a whole. This plenary day was initially planned for four months after the course start date, but was delayed until six months after the launch when it became clear that completion in a four-month time frame was unrealistic for many students.

\section{THE EVALUATION}

The aims of the evaluation were to explore:

* Whether the course content was commensurate with the perceived needs of health care support workers;

* Whether the level of the work was appropriate for health care support workers;

* Whether the support for those undertaking the course was adequate;

* Whether the course was perceived by health care support workers to assist them in their work with children with complex needs;

* Whether the format used (hard copy) was acceptable, or whether staff would have preferred a CD ROM or web-based option.

This project could be regarded as a form of action research, as it represents a formal evaluation of an innovation conducted by practitioners in their own field in response to an identified need (Rolfe, 2001). Pragmatism as well as methodological considerations inform action research (Hope \& Waterman, 2003). Research models should be formulated and used (Nunes \& McPherson, 2003), but these may need to be adapted to enable exploration within practical constraints, for example, time and resources. The aim of this programme was to bring about a direct improvement in education practice rather than to generate knowledge for its own sake (Rolfe, 1998), with a direct relationship between inquiry and its practical application (Hammersley, 2004; Hope \& Waterman, 2003). A qualitative approach to evaluation was adopted in this instance, with the goal of exploring the real-life experience of individuals who undertook the course, rather than to quantify facts (Banyard \& Grayson, 2000). Patton (1987) considers qualitative methods valuable for exploring individuals' potentially altering perceptions over time, making them appropriate for this evaluation to explore individual's views over the entire course.

\section{METHODS}

Questionnaires were selected as a data collection tool. Since a low response rate and misinterpretation of questions are potential problems with questionnaires (Le May, 2001), attempts were made to overcome this. This was accomplished by piloting the questionnaires, giving assurance of confidentiality, explaining why the evaluation was being conducted, allowing time for students to complete the questionnaires during study days and providing a pre-paid envelope for return of questionnaires not completed at the time. An alternative approach to data collection would have been interviews. These allow depth of meaning to be sought and are less prone to misinterpretation than questionnaires (Polit \& Hungler, 1999). However, reactions to the interviewer may bias responses, social desirability bias may be increased in comparison with questionnaires, and anonymity is lost (Le May, 2001; Banyard \& Grayson, 2000). In this instance, because the participants were students, this might have limited their willingness to give honest and critical feedback, especially in face-to-face encounters.

Given the diverse geographical locations that students came from, and the need to focus on course support within a realistic travel time frame at study days, it would also have been logistically difficult to co-ordinate interviews with all the students. Attempting this approach would have incurred significant additional expense and seemed likely not to be successful. This illustrates one of the key points in action research, where methods must be tempered by consideration of practical realities. Questionnaires were therefore selected.

What needs does/do the child/children you care
for have?
Which areas of care have you found especially
challenging in your work to date?
Why are you doing this course?
What do you hope to gain from the course?
Do you have any specific aims on this course?
Do you have any concerns about doing the course?
Any other comments?

Figure 1. Questionnaire: First day of the course.

A questionnaire was distributed to all course members on the first course day (see Figure 1). On the second study day, a followup questionnaire was distributed examining:

* The content and format of the course materials;

* The support available;

* Whether their aims were being met;

* Whether the course helped them to address the aspects of care they found challenging;

* Their current/ongoing specific aims or concerns.

On completion of the course, another questionnaire was distributed regarding these elements. This information was sought on both occasions because students' views may alter during the course of the study (Peeke, 1993) and they studied the workbooks in different orders depending on the needs of the child and family for whom they cared for, and their existing knowledge and experience. To cover their responses to all the workbooks, and to ascertain changes in perspective over time, it was necessary to elicit this information on both occasions (see Figure 2).

How many and which of the workbooks have you
Completed to date?
Generally, how have you found the level of the
workbooks?
Has the content been relevant to your practice?
How have you found the activities (for example, too
easy, too hard, unclear, not applicable)?
Are there any specific issues that you have come
across on the course so far which you have found
difficult or challenging?
Is the amount of work what you expected, more or less?
Do you feel the support available has been adequate?
Any other comments?

Figure 2. Questionnaire: Review Day. 


\section{SAMPLE}

The sample comprised all the students undertaking this course. Sixteen students were enrolled and so this was the maximum sample size possible. A small sample size is typical of qualitative enquiry and represented the reality of the situation studied.

The students had a variety of backgrounds in education and practice. All had completed a standard work-based orientation and training programme provided by Clinovia. Four held NNEB qualifications (diploma in nursery nursing) and had worked as nursery nurses in a variety of hospital and community settings. One had completed a Higher National Diploma in health and social care, and one had an Advanced Diploma in health care. Others were at various stages of undertaking National Vocational Qualification training. This mix appears to represent the reality which will always exist in education for this group.

During the course, two students discontinued their employment with Clinovia and were thus lost to the study; a third student was unable to complete the work due to a combination of personal and work-related circumstances and deferred participation in the course. All other course members completed and returned all three questionnaires.

\section{ETHICAL ISSUES}

Students can be perceived as a vulnerable population (Burns \& Grove, 1993). In this instance they may have been concerned that negative feedback could adversely affect their course work. This was a consideration when deciding to use questionnaires rather than face-to-face encounters. To ensure anonymity and confidentiality, data were coded with numbers, not names of individuals, and participants were assured that the information would be regarded as confidential (Barker, 1991). Consent was considered explicit by return of questionnaires.

\section{DATA ANALYSIS}

Constant comparative analysis was used for data analysis, as described by Hewitt-Taylor (2001). Codes were generated from the data gathered. Although literature-based codes can be useful and speed up the analysis procedure, they can also impede the development of new ideas (Strauss \& Corbin, 1990). In this case, there is limited literature on the education and training needs of health care support workers who care for children requiring assisted ventilation, and thus the development of literature-based codes would be problematic.

\section{RESULTS}

The response rate was $100 \%$ (excepting those who left the course).

\section{Students' course aims}

All the students stated aims that included the themes of developing their knowledge, understanding and skills. For example, individuals wanted to 'gain knowledge of caring for patients with complex needs [children and adults]'. Eight felt that completing the course would enhance their care provision, for example that it would 'enable me to provide high standards of care'. One felt that the knowledge gained would increase her confidence in practice. Some students' aims related to specific areas of knowledge, for example: 'gain more insight into working with a sick child at home' and 'gain more knowledge of children [not cared for them before]'. Others identified that there were probably areas where 'I don't know what I don't know' and hoped to gain awareness of knowledge deficits as well as beginning to learn in these areas. Providing more holistic care for the child and family was identified as an aim by four students. All the students had been selected by their employer as being suitable for the pilot course, but only one identified this as her reason for attendance.

\section{Students' concerns}

Students' concerns almost all related to workload issues, with all except one making comments to this effect. This was especially problematic where students were concurrently engaged in other study. One cited her main concern as 'managing workload' - 'doing NVQ 3 [as well]' (National Vocational Qualification at level 3. NVQs can be taken at levels 1 to 5, with level 3 involving the application of knowledge in a broad range of work activities.) Combining work and study was an initial concern for many of the students, with one commenting during the final evaluation that she had found it 'hard to juggle work and study'. The total volume of work was initially a cause of concern but, as the students began to discuss their study plans and complete the workbooks, this became less problematic. The course length was considered inadequate by three students, despite being lengthened from four to six months. During and on completion of the course, eight students considered that the workload was as they had expected, with six finding it more than expected at the halfway points (two having left the course) and five at the end point (three having left). None found that the workload was lighter than expected.

Only one student cited the lack of classroom environment as a concern, although another felt that sustaining motivation might be difficult, which may have been linked with the lack of direct contact with other students. One stated that her main concern was the 'actual writing of assignments'.

\section{Content}

By the eight week review day, three students had completed one of the eight workbooks (two of these had been caring for an adult, which made the workbooks less relevant to their needs, and one had other NVQ course commitments and ultimately delayed completing this course), three had completed two, two had completed three, four had completed four, one had completed five and one seven. Two had left the course. By the end of the course, all the students had either completed all the workbooks or had completed those their nursing co-ordinators had advised them were relevant to their workload (for example, those caring for adults did not all complete the workbook on congenital heart defects). However, the overall view was that completing all the workbooks within a six-month time frame had been a challenge.

The level of the course content was consistently described as acceptable by the majority of students. However, the terminology used was sometimes problematic, especially in relation to pathophysiology and medical or technical interventions. One commented 'terminology [is difficult] especially if it is not something I am familiar with'. Two also suggested that things needed to be 'made simpler' and one felt that they needed 'smaller amounts per workbook'. The majority of participants felt that a glossary of terms would have helped them. 


\section{Links between theory and practice}

Generally, the range of subjects was seen as appropriate, covering the needs of the children cared for and the content relevant to practice. Six students felt that all the workbooks were relevant, five felt that about three quarters were, one felt that all except cardiology were relevant (as her patient did not have any cardiac problems), another felt that all except pain were (as she reported that the child she cared for did not have any pain). Two of those who felt that approximately three quarters of the workbooks were relevant commented that the limit to relevance was that they were caring for an adult, not a child, and one felt that what was not relevant at this point in time would be in the future.

On course completion, all the students indicated that they had achieved their aims, and that they appreciated a course which addressed the specific needs of their client group.

\section{Evaluation of support}

Overall, the support available from local education and nursing co-ordinators was felt to be good and students valued the amount of time their co-ordinators spent in assisting them with their work. However, when local co-ordinators left their posts, or where workloads were heavy for the time that could have been spent in education activities, the support students felt they received was reduced. Students who sought support from the University also cited this as adequate, although most used local support. One stated that 'monthly meetings with the co-ordinator would be good' and one group found that once they organised regular meetings their coursework became much more manageable. Two emphasised the need for ongoing support and stated that '[the course is] enjoyable now that I have support from the team leader'.

\section{Method of presentation}

The workbook format was generally preferred over the idea of CD ROM or web-based learning. Students could take the workbooks into the workplace with them and study during quiet periods. Some felt able to use CD ROMs but still valued having hard copy. Many students were not sufficiently confident in using computers to want to access course material by CD ROM, and the cost and availability of using web-based materials would have been an issue for most.

The activities-based approach was generally well evaluated. Overall comments on the activities included 'very relevant', although one student found them 'challenging but not too hard'. However, there was an initial lack of clarity about the volume of work to be produced, with one student commenting: 'bit difficult to judge how much to write [for each activity]'. There was also initial confusion over the activities and the assignment because the activities were not graded. The co-ordinators simply gave pointers to thinking and application of the course material. Three students felt that the 'wide range' of activities was beneficial, given the range of children cared for but, in contrast, one course member felt that the activities 'could be more specific'.

The course aimed to be flexible regarding the order of workbook completion, and the weighting and time devoted to each workbook or section of workbook. Although students generally appreciated this, one commented that 'loose structure useful but difficult to follow'.

\section{DISCUSSION}

This pilot study indicates that a course related to caring for children who require long-term assisted ventilation specifically designed for health care support workers is practically viable and appears to merit development. However, the study has highlighted a number of issues that require consideration in course development. Although the students and their supervisors were enthusiastic for this course to be developed into a more formal course with accreditation, it does not fit neatly into the more generalist NVQ pathway. A specific certificate level course (120 certificate level credits) is therefore being developed and validated, which will allow increased flexibility over time as well as breaking the workbooks into more manageable chunks to make the content less daunting at the outset. Developing the course to full certificate level also requires more academic assessment. The course content will therefore be broken into 20 credit units with an assignment attached to each.

Planning work and study will always be an issue for courses where staff work full-time as well as studying. Having completed the pilot unit, it will be possible to give a more realistic suggestion of timescale for completing each workbook to guide employers and students. Greater flexibility will also be available as the course units can be taken over a maximum of two years.

It is clear that students require and value adequate support in their learning activities. This supports other work in distance learning (Rolfe, 1998; Hewitt-Taylor, 2003) and indicates that student support is not an area that can be reduced. It is also something that students may need assistance to access - those who reported having problems accessing support did not seem to use the range of options available (Hurd et al., 2001; McPhee \& Nohr, 2000). Students who accessed the most support appeared to find the course the most enjoyable, relevant and manageable. Carnwell (2000) suggests that negotiation between students and tutors is an important part of the support in distance learning, so that all are clear on their roles and responsibilities. This is an area that will be focused on in future, and the need to use support and the range of resources available will be emphasised to students. Supervisors will be made more aware that students may not be confident in accessing support.

The activities-based approach to learning was broadly successful as has been seen in post-registration nurse education (HewittTaylor, 2003). However, it is important that students are aware of what is being academically assessed and what is a part of their coursework. Both aspects of learning are important, and the intention is not to detract from the activities that are intended to apply theory to practice. This requires careful management because, as Wass et al. (2001) and Rideout (2001) propose, students tend to focus on assessment over learning opportunities.

Although there is generally much enthusiasm among education providers for the use of electronic learning media, this was not a popular option for these students. The availability of computer resources for individuals was one issue, and the practicalities of using electronic learning media when caring for children in the home environment meant that text-based resources were seen as more user friendly. This is a consideration for the future design of this course, but also for similar courses dealing with individuals who may not have access to information technology on a day-today basis (Hewitt-Taylor, 2003). 
The findings from this evaluation are limited as the intention was to determine the viability of ongoing courses and to inform course developments, rather than to produce results that could be widely generalised. There is the potential for students to give responses that they feel the evaluation team wish to hear, rather than reality. It is also possible that, despite being open-ended questions to encourage mixed responses, students felt led to giving a positive response. In addition, because this is the only course of this nature available nationally, a positive response may simply mean that it is better than nothing. However, the suggestion that such a course has the potential to meet the needs of a developing population of care staff is valuable and the comments made have enabled the planning of ongoing developments in course content and organisation.

\section{CONCLUSION}

With the increasing population of children requiring long-term assisted ventilation, there is a need to support staff in developing their skills and knowledge to support them. This includes specific input for staff who provide their day-to-day care. While debate continues over who should provide care (for example, whether such care should be provided by registered nurses or health care support workers) it is appropriate to make inroads into ensuring that those who are providing care are appropriately trained and educated.

The diverse geographical location of the population of children needing long-term assisted ventilation means that distance learning is a suitable method of education provision. There is some evidence from this pilot study that this method can be successfully used to augment in-service training for health care support workers. The Department of Health (2001) suggests that, wherever possible, this type of education should be formally recognised and accredited. The aim is therefore to develop the piloted course into an accredited, formally recognised and benchmarked qualification for those who provide this type of care.

In developing the course, a coherent but flexible structure was seen as essential. The flexibility of the course is important, given the diverse needs of children and their families. However, in some cases, greater structure might be useful and thus a structured but flexible study pathway is the aim. Adequate provision of support for students and facilitators, clarity for all parties over role expectations, support available and how this should be accessed and used, along with responsibilities in using this, are necessary.

The course is now being developed into a series of 20 certificate level units of study, which cover the diverse needs of the population of children who require long-term assisted ventilation. These will enable the staff who care the children to access a total of 120 credits and gain a Certificate in Higher Education in this area. There will be some compulsory elements and some groups of units from which students may select one or more units, dependent on their specific needs. The timescale will be flexible, but students will be required to plan their intended study pathway and completion dates to avoid feelings of being overwhelmed by work or not having a clear aim. Ongoing evaluation of the programme will be an integral part of the course development.

\section{REFERENCES}

Aday LA, Wegener DH. (1998) Home care for ventilator-assisted children: implications for the children, their families, and health policy. Journal of Child Health Care 17 (2): 112-120.

Balling K, McCubbin M. (2001) Hospitalized children with chronic illness: parental caregiving needs and valuing parental expertise. Journal of Pediatric Nursing 16 (2): 110-119.

Banyard P, Grayson A. (2000) Introducing Psychological Research. (2nd Edition) Palgrave, Basingstoke.

Barker PJ. (1991) Interviews. In: Cormack DFS. (Ed.) The Research Process In Nursing. (2nd Edition) Blackwell, London. pp.207-214.

Boosfeld B, O'Toole M. (2000) Technology dependent children: transition from hospital to home. Paediatric Nursing 12 (6): 20-22.

Burns N, Grove, SK. (1993) The Practice Of Nursing Research. (2nd Edition) WB Saunders, London.

Carnwell R. (2000) Pedagogical implications of approaches to study in distance learning: developing models through qualitative and quantitative analysis. Journal of Advanced Nursing 31(5): 1018-1028.

Department of Health. (2001) Working Together - Learning Together. Department of Health. London.

Glendinning C, Kirk S. (2000) High tech care: high skilled parents. Paediatric Nursing 12 (6): 25-27.

Gould D, Carr G, Kelly D, Brown P. (2004) Seconding health care assistants to a pre-registration nursing course: evaluation of a novel scheme. NTResearch 9 (1): 50-64.

Hammersley M. (2004) Action research: a contradiction in terms? Review of Education 30 (2): 165-181.

Hewitt-Taylor J. (2001) Use of constant comparative analysis in analysing qualitative research. Nursing Standard 15 (42): 39-42.

Hewitt-Taylor J. (2003) Facilitating distance learning in nurse education. Nurse Education in Practice 3 (1): 23-29.

Hewitt-Taylor J. (2004) Children requiring long-term ventilation: staff education and training. Intensive and Critical Care Nursing 20 (2): 93-102.

Hope KW, Waterman HA. (2003) Praiseworthy pragmatism? Validity and action research. Journal of Advanced Nursing 44 (2): 120-127.

Jardine E, Wallis C. (1998) Core guidelines for the discharge home of the child on long-term assisted ventilation in the United Kingdom. Thorax. 53 (9): 762-767.

Jardine E, O'Toole M, Paton JY, Wallis C. (1999) Current status of long-term ventilation of children in the United Kingdom: a questionnaire survey. British Medical Journal 318 (7179): 295-299.

Kirk S. (2001) Negotiating lay and professional roles in the care of children with complex health care needs. Journal of Advanced Nursing 34 (5): 593-602.

Kirk S, Glendinning C. (2002) Supporting 'expert' parents: professional support and families caring for a child with complex health care needs in the community. International Journal of Nursing Studies 39 (6): 625-635.

Le May A. (2001) Making Use of Research. South Bank University, London.

Lumeng JC, Nelson VS, Hurvitz EA. (1999) Perinatal spinal cord injury requiring long-term home mechanical ventilation: a report of four cases. Pediatric Rehabilitation 3 (2): 53-58.

McFazdean E. (2001) Supporting virtual learning groups. Part 2: An integrated approach. Team Performance Management 7 (5/6): 77-92.

McPhee W, Nohr C. (2000) Globalisation and the cultural impact on distance education. International Journal of Informatics 58-9 (3): 291-295.

National Audit Office. (2001) Educating and training the future health care professional workforce for England. National Audit Office, London. 


\section{* Children who require long-term assisted ventilation: education and training for care staff *}

National Health Service Executive (1997a) Evaluation of the Pilot Project Programme for Children with Life Threatening Illness. NHSE, London.

National Health Service Executive. (1997b) A Bridge to the Future:

Nursing Standards, Education and Workforce Planning in Paediatric Intensive Care: Report of the Chief Nursing Officer's Task Force. London, Department of Health.

Neufeld SM, Query B, Drummond JE. (2001) Respite care users who have children with chronic conditions: are they getting a break? Journal of Pediatric Nursing 16 (4): 234-244.

Nunes MB, McPherson M. (2003) Action research in continuing professional distance education. Journal of Computer Assisted Learning 19 (4): 429-437.

O'Brien ME. (2001) Living in a house of cards: family experiences with long-term childhood technology dependence. Journal of Pediatric Nursing 16 (1): 13-22.

Olsen R, Maslin-Prothero P. (2001) Dilemmas in the provision of own-home respite support for parents of young children with complex health care needs: evidence from an evaluation. Journal of Advanced Nursing 34 (5): 603-610.

Rideout E. (2001) Evaluating student learning. In: Rideout E (ed.) Transforming Nurse Education Through Problem-based Learning. Jones and Bartlett, London, Chapter 9, pp.215-237.

Noyes J. (2002) Barriers that delay children and young people who are dependent on mechanical ventilators from being discharged from hospital. Journal of Clinical Nursing 11 (1): 2-11.

Peeke G. (1993) Issues and problems in implementing student centred learning with adults. Journal of Teacher Development 2 (1): 46-52.

Polit DF, Hungler BP. (1999) Nursing Research: Methods, Appraisal And Utilisation. (6th Edition) Lippincott, Philadelphia, USA.

Robinson C, Jackson P, Townsley R. (2001) Short breaks for families caring for a disabled child with complex health needs. Child and Family Social Work 6 (1): 67-75.

Rolfe G. (1998) Expanding Nursing Knowledge: Understanding and Researching our own Practice. Butterworth Heinemann.

Rolfe G. (2001) Research: Knowledge and Practice. South Bank University, London.

Strauss A, \& Corbin J. (1990) Basics of Qualitative Research: Grounded Theory Procedures and Techniques. Sage, London.

Ward T, Worswick J, Inglis A, Perera M, Rehman K. (2003) Children with complex, continuing health needs and/or life limiting conditions.

Children's National Service Framework: Disabled Children EWAGE task group. January 2003.

Warr JG. (1998) An evaluative study into the effectiveness of level 3 National Vocational Qualification support staff to nurses. Nurse Education Today 18 (6): 505-516.

Wass V, Van der Vleuten C, Shatzer J, Jones R. (2001) Assessment of clinical competence. The Lancet 357 (9260): 945-949

\section{Continuing clinical care - out of hospital, into the home}

Clinovia is Britain's most experienced community based healthcare provider supporting the NHS through the provision of high quality, tailored home healthcare services.

Patients and their families are happier and more relaxed when they can be treated in the comfort and convenience of their own home. This can often mean a better response to

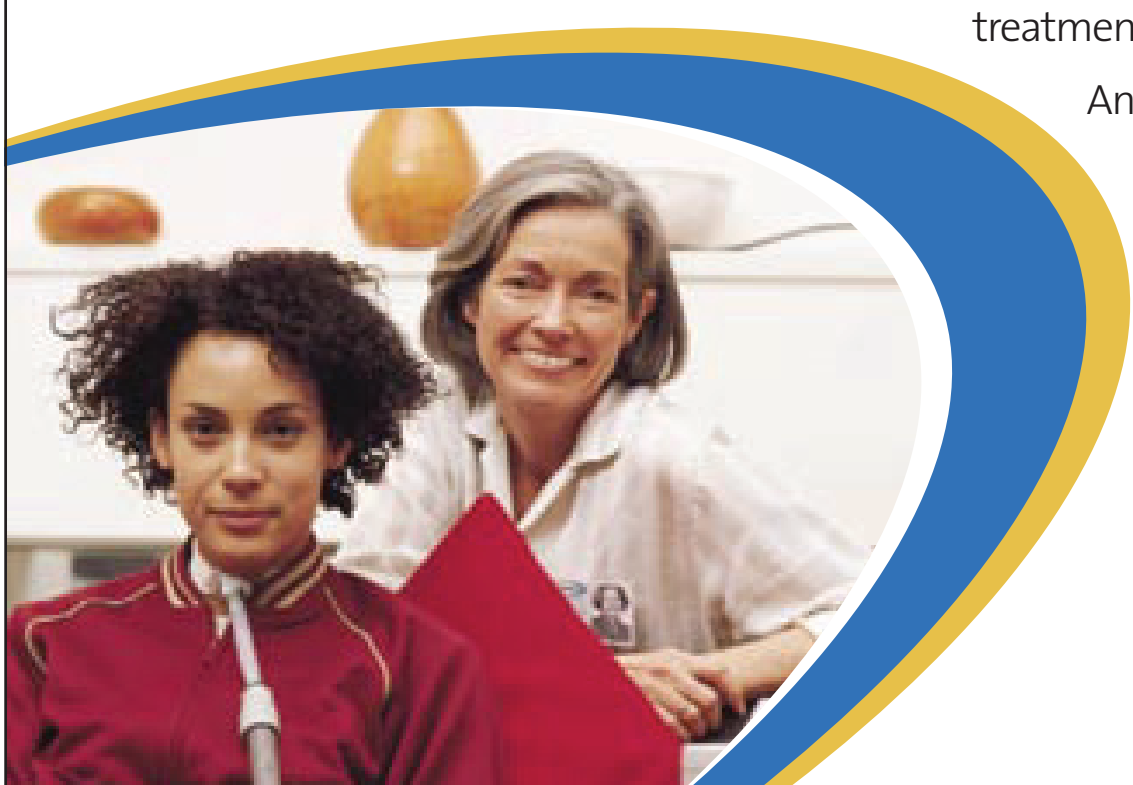

And, almost without exception, patients receiving extended care in the comfort and privacy of their own home will enjoy a better quality of life.

Head Office: Clinovia Ltd, 7 Coldharbour Pinnacles Estate, Lovet Road, Harlow, Essex CM19 5JL Tel: 01279456789 Fax: 01279419900 www.clinovia.co.uk 